\title{
Catalytic Asymmetric [8+2] Annulation Reactions Promoted by a Recyclable Immobilized Isothiourea
}

\begin{abstract}
Higher order cycloadditions constitute an efficient approach towards the construction of medium to large ring systems. However, enantioselective versions of these transformations remain scarce, which hampers their deployment in medicinal chemistry, or any other discipline where homochirality is deemed crucial. Herein, we report a novel methodology for the production of enantioenriched cycloheptatrienes fused to a pyrrolidone ring, based on an isothiourea-catalyzed periselective [8+2] cycloaddition between chiral ammonium enolates (generated in situ from carboxylic acids) and azaheptafulvenes. The resulting bicyclic compounds can be hydrogenated but, most remarkably, they can also undergo a completely regioselective [4+2] cycloaddition with active dienophiles to give rise to architecturally complex polycyclic compounds in a straightforward manner.
\end{abstract}

Shoulei Wang, ${ }^{[a]}$ Carles Rodríguez-Escrich, ${ }^{[a]}$ and Miquel A. Pericàs ${ }^{*[a],[b]}$

Cyclic structures are ubiquitous in natural products and pharmaceutical compounds. Among the myriad strategies devised to construct such architectures, ${ }^{[1]}$ cycloadditions constitute one of the most efficient approaches in terms of atom

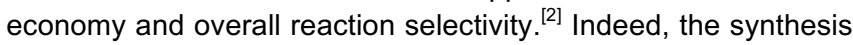
of rings having up to 6 members by either thermal or photochemical $[2+2],{ }^{[3]}[3+2]^{[4]}$ and $[4+2]^{[5]}$ processes is well established. On the other hand, the synthesis of medium and large rings through reactions involving more than six $\pi$ electrons (the so called higher order cycloadditions ${ }^{[6]}$ ) represents an interesting approach to build complex polycyclic compounds and bridge-containing carbocyclic products. However, this alternative $^{[7]}$ is often hampered by lack of periselectivity and other competing side reactions ${ }^{[8]}$ which, along with the extra challenge of transferring chiral information across a number of bonds, can explain the lack of general methods to produce enantioenriched compounds via higher order cycloadditions. ${ }^{[9]}$

Heptafulvenes $^{[10]}$ and their heteroanalogues (tropone, ${ }^{[11]}$ tropothione ${ }^{[12]}$ and the azaheptafulvenes $\left.{ }^{[13]}\right)$, a subclass of the "non-benzenoid aromatic compounds" family, have been recognized as important synthons for higher order cycloadditions due to their conjugated cyclic polyolefin systems. Among all the

[a] Mr. Shoulei Wang, Dr. Carles Rodríguez-Escrich, Prof. Dr. Miquel A. Pericàs

Institute of Chemical Research of Catalonia (ICIQ), The Barcelona Institute of Science and Technology

Av. Països Catalans 16, 43007 Tarragona, Spain

E-mail: mapericas@iciq.es

[b] Prof. Dr. Miquel A. Pericàs

Departament de Química Inorgànica i Orgànica

Universitat de Barcelona

08080 Barcelona, Spain

Supporting information for this article is given via a link at the end of the document. possible reaction pathways that can be attained with heptafulvene derivatives, the [8+2] cycloaddition provides a direct approach to highly functionalized bicyclic [5.3.0] rings, which are core scaffolds in numerous natural products. ${ }^{[14]}$ Since the first $[8+2]$ cycloaddition introduced by Wiley et al. in $1960,{ }^{[15]}$ various methodologies to carry out this process have been described, ${ }^{[16]}$ but enantioselective versions remain scarce: to the best of our knowledge, a metal-mediated cycloaddition reported by the Feng group $^{[17]}$ (Scheme 1a) and an organocatalytic cycloaddition described by the Jørgensen group ${ }^{[18]}$ (Scheme $1 b$ ) are the only catalytic enantioselective [8+2] reactions found in the literature. Therefore, the development of a general and efficient approach for the peri-, regio- and stereoselective [8+2] cycloaddition reaction remains a highly attractive and challenging target.

We envisioned that chiral ammonium enolates ${ }^{[19]}$ (derived from activated carboxylic acids and isothioureas) could be suitable reaction partners to undergo catalytic [8+2] cycloadditions with azaheptafulvenes, which would play the role of $8 \pi$ dipolarophiles. Herein, we present the implementation of this strategy, which leads to enantioenriched 7,5-fused heterocyclic compounds (Scheme 1c). The cycloheptatrienes generated can be either hydrogenated or derivatized in a Diels-Alder reaction that affords bridged polycyclic products in a highly regioselective manner.

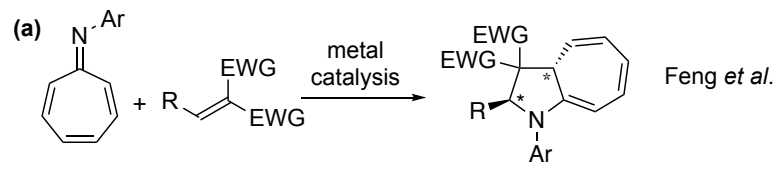

(b)<smiles>CC(C)(C)CCCCOC(C)(C)C</smiles><smiles>O=C1C=CCCC1</smiles>
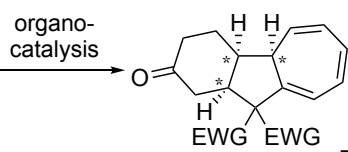

Jørgensen et al. (c)

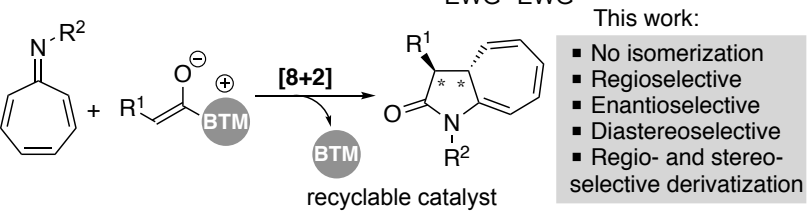

Scheme 1. Enantioselective versions of [8+2] cycloaddition.

Based on our previous works on formal hetero-[4+2] cycloadditions promoted by an immobilized isothiourea of the benzotetramisole (BTM) type,$^{[19 e, 19 g]}$ a model reaction of the azaheptafulvene $2 \mathrm{a}$ with phenylacetic acid $3 \mathrm{a}$ catalyzed by polystyrene-supported BTM was investigated (Table 1). After a preliminary study, we established a standard protocol based on 
the use of immobilized isothiourea $\mathbf{1 b}$, PivCl and DBU in $\mathrm{CH}_{2} \mathrm{Cl}_{2}$ at $0{ }^{\circ} \mathrm{C}$. Under these conditions, azaheptafulvene $2 \mathrm{a}$ was fully consumed and the desired [8+2] product $4 \mathbf{a}$ could be obtained in high stereoselectivity (96:4 dr, $91 \%$ ee, entry 1$)$. Previously reported possible side products, ${ }^{[17]}$ such as those derived from isomerization of the cycloheptatriene unit, were not detected. For the sake of comparison, we also tested the homogeneous isothiourea catalyst $\mathbf{1 a}$, but only moderate diastereoselectivity was observed (entry 2). This suggested that the additional stereocenter present in $\mathbf{1 b}$ was critical, which was confirmed by the results obtained with the homogeneous analog 1c (entry 3 ). Likewise, other bases like $i-\mathrm{Pr}_{2} \mathrm{NEt}$ and $\mathrm{Et}_{3} \mathrm{~N}$ resulted in lower enantioselectivities, albeit conversions and diastereoselectivities remained the same (entries 4 and 5). Substitution of the activating reagent (pivaloyl chloride) for $\mathrm{BnCOCl}$ and $\mathrm{TsCl}$ (entries 6 and 7) did not improve the results either, whereas other solvents screened had a negative impact on both reactivity and stereoselectivity (entries 8-10). In addition, decreasing the catalyst loading to $5 \mathrm{~mol} \%$ resulted in lower reactivity and stereoselectivity (entry 11$)$.

Table 1. Optimization of reaction conditions. ${ }^{[a]}$

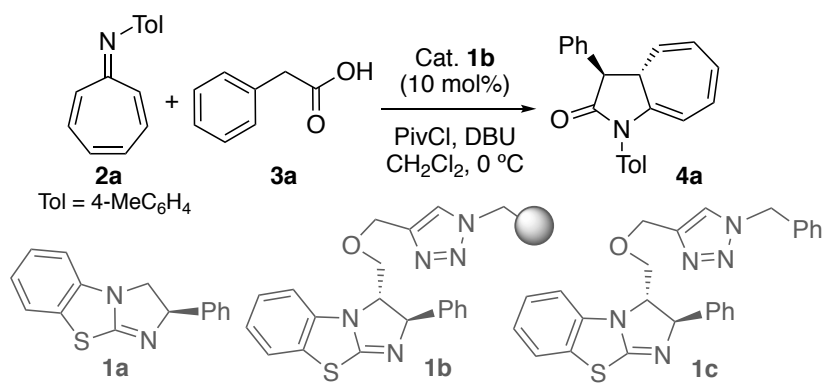

\begin{tabular}{|c|c|c|c|c|}
\hline Entry & $\begin{array}{l}\text { Modification of the } \\
\text { standard conditions }\end{array}$ & Conv. [\%] & $\mathrm{dr}^{[\mathrm{b}]}$ & $\mathrm{ee}^{[\mathrm{c}]}[\%]$ \\
\hline 1 & None & $>95$ & $96: 4$ & 91 \\
\hline 2 & $1 \mathrm{a}$ as the catalyst & $>95$ & $75: 25$ & 91 \\
\hline 3 & 1c as the catalyst & $>95$ & $96: 4$ & 90 \\
\hline 4 & $i$ - $\mathrm{Pr}_{2} \mathrm{NEt}$ as the base & $>95$ & $96: 4$ & 87 \\
\hline 5 & $\mathrm{Et}_{3} \mathrm{~N}$ as the base & $>95$ & $96: 4$ & 70 \\
\hline 6 & $\mathrm{TsCl}$ instead of $\mathrm{PivCl}$ & 65 & $97: 3$ & 90 \\
\hline 7 & $\mathrm{BnCOCl}$ instead of $\mathrm{PivCl}$ & 55 & $96: 4$ & 91 \\
\hline 8 & THF instead of $\mathrm{CH}_{2} \mathrm{Cl}_{2}$ & 88 & $98: 2$ & 20 \\
\hline 9 & $\mathrm{Et}_{2} \mathrm{O}$ instead of $\mathrm{CH}_{2} \mathrm{Cl}_{2}$ & 20 & $76: 24$ & - \\
\hline 10 & $\mathrm{CHCl}_{3}$ instead of $\mathrm{CH}_{2} \mathrm{Cl}_{2}$ & $>95$ & $97: 3$ & 88 \\
\hline 11 & $5 \mathrm{~mol} \%$ catalyst & 78 & $97: 3$ & 84 \\
\hline
\end{tabular}

[a] Reactions performed on a $0.1 \mathrm{mmol}$ scale. [b] Determined by ${ }^{1} \mathrm{H}$ NMR spectroscopy. [c] Determined by chiral HPLC.

After the preliminary optimized reaction conditions passed the stress tests summarized in Table 1, we turned our attention to validating the generality of this [8+2] annulation reaction. As illustrated in Scheme 2, a broad range of substituted phenylacetic acids bearing electron-withdrawing and electron-donating substituents are tolerated, giving rise to the cycloadducts $4 \mathrm{a}-\mathbf{4 h}$ in good yields (65-80\%) and high enantioselectivities (90-97\%) and diastereoselectivities (>20:1). The bulkier 2-naphthylacetic acid also proved to be a good substrate, delivering the desired product $4 \mathbf{i}$ with comparable yield and stereoselectivity $(>20: 1 \mathrm{dr}$, $90 \%$ ee). A heteroaromatic moiety could also be accommodated in 3 , as shown by the synthesis of the corresponding 2-thienyl derivative (4j, $83 \%$ yield, $93 \%$ ee); albeit the dr decreased, the result was still more than satisfactory $(12: 1)$. The system also worked with unsaturated carboxylic acids, providing $\mathbf{4 k}$ in good yield and dr (13:1) but moderate enantioselectivity; however, using purely aliphatic acids resulted in no conversion. The absolute configuration of $\mathbf{4 b}$ could be ascertained by $\mathrm{X}$-ray diffraction analysis, ${ }^{[20]}$ that of $\mathbf{4 a , c - k}$ being assigned by analogy.

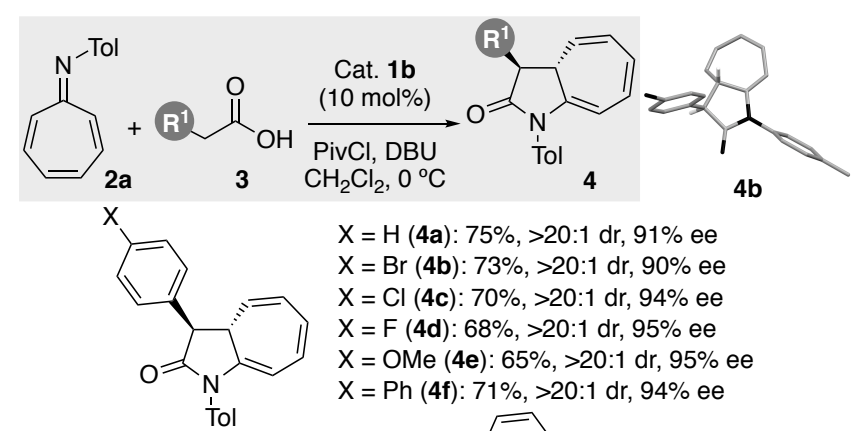

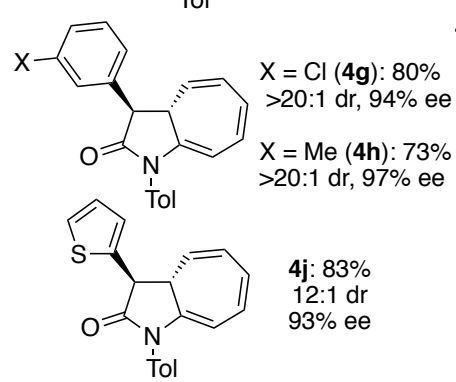<smiles>O=C1[C@H](/C=C/c2ccccc2)[C@@H]2C=CC=CC=C2N1[Al]</smiles>

4i: $81 \%$ $20: 1 \mathrm{dr}$ $90 \%$ ee $\mathrm{X}=\mathrm{Me}(4 \mathrm{~h}): 73 \%$
$>20: 1 \mathrm{dr}, 97 \%$ ee 4k: $70 \%$ $13: 1 \mathrm{dr}$
$47 \%$ ee

Scheme 2. Scope of substituted arylacetic acids. ${ }^{[a]}$

Next, we set our sights on the evaluation of various $N$-aryl substituted 8-azaheptafulvenes in this cycloaddition. In general, the [8+2] annulation reactions were insensitive to electronic changes on the aromatic $N$-substituent on azaheptafulvenes $\left(R^{2}\right)$. A series of cycloheptatriene-fused pyrrolidone derivatives (4I-4r, Scheme 3) could be accessed in good yields (70-85\%), and high stereoselectivities $(90-98 \%$ ee, $\mathrm{dr}>20: 1$ in all cases).

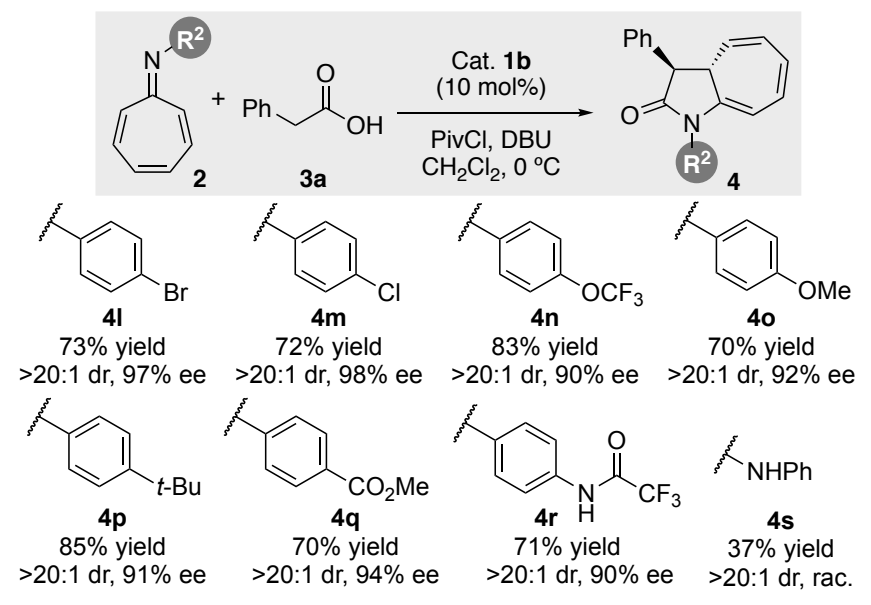

Scheme 3. Reactions performed on a $0.1 \mathrm{mmol}$ scale (see Supporting Info). ${ }^{[a]}$

Further attempts to explore the scope using tropone phenylhydrazone as substrate gave the expected product (4s) in low yield and ee, but high diastereoselectivity. Disappointingly, 
no [8+2] product was observed with a tropolone derivative, bearing a methoxy substituent on $\mathrm{C}_{2}$ of the 8-azaheptafulvene.

From a practical perspective, the possibility of recycling the immobilized isothiourea catalyst $\mathbf{1 b}$ is appealing due to the inherent reduction of costs and increase of overall efficiency. To this end, the reaction between $\mathbf{2 a}$ and $\mathbf{3 a}$ was carried out in a series of experiments where catalyst $1 \mathbf{b}$ was recovered by simple filtration and reused by adding fresh reactants after each run. No significant decrease of stereoselectivity was observed and only marginal erosion in the yield took place over the first four runs (Scheme 4). The accumulated TON for these recycling experiments was 44.7, which shows the advantage of this strategy over the usual approach, where a maximum TON of 10 can be achieved with $10 \mathrm{~mol} \%$ catalyst loading.
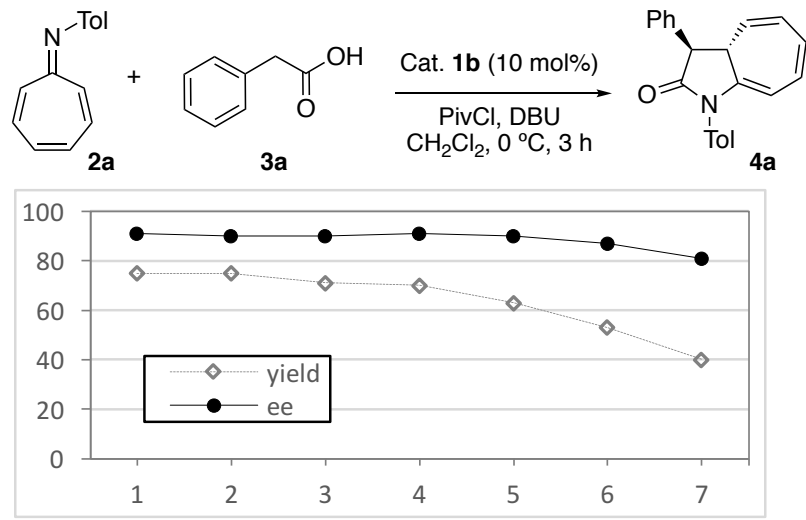

Scheme 4. Recyclability tests.

To demonstrate the synthetic potential of this metodology, we decided to test the behaviour of the [8+2] cycloadducts 4 as $4 \pi$ components in a Diels-Alder reaction. Thus, cycloheptatrienefused pyrrolidone $\mathbf{4 a}$ was treated with $\mathrm{N}$-phenyl triazolinedione $\mathbf{5 a}$ in $\mathrm{CHCl}_{3}$ at room temperature. To our delight, the [4+2] product 6a was obtained as a single regioisomer in good yield and high stereoselectivity (>20:1 dr, 87\% ee). The general applicability of the Diels-Alder reaction between the cycloadducts 4 and $N$ substituted triazolinediones $\mathbf{5}$ was subsequently investigated.

Table 2. Diels-Alder reactions of 4 with different substituted triazolinediones. $^{[\mathrm{a}]}$<smiles>[R]C1C(=O)N([AlH2])C2=CC=CC=C[C@H]21</smiles>

4

\begin{tabular}{ccccc}
\hline Entry & $\mathrm{X}$ & $\mathrm{R}^{1}$ & $\mathrm{dr}$ & Yield [\%] \\
\hline 1 & $\mathrm{Ph} \mathrm{(6a)}$ & $\mathrm{Ph}$ & $>20: 1$ & $75^{[\mathrm{b}]}$ \\
2 & $\mathrm{Ph} \mathrm{(6b)}$ & $4-\mathrm{BrC}_{6} \mathrm{H}_{4}$ & $>20: 1$ & 80 \\
3 & $\mathrm{Et} \mathrm{(6c)}$ & $\mathrm{Ph}$ & $>20: 1$ & 70 \\
4 & $n$-Bu (6d) & $\mathrm{Ph}$ & $>20: 1$ & 77 \\
\hline
\end{tabular}

[a] Reactions performed on a $0.1 \mathrm{mmol}$ scale (see Supporting Information). [b] $87 \%$ ee determined by chiral HPLC.

As shown in Table 2, structurally unique bridged-polycyclic products 6 containing one quaternary and three tertiary stereocenters could be efficiently prepared in a highly regio- and stereoselective manner via a $[8+2] /[4+2]$ reaction sequence. The structure and absolute configuration of $\mathbf{6}$ were confirmed by X-ray diffraction analysis of $\mathbf{6 b} .^{[20]}$ To further prove the versatility of these cycloadducts, we demonstrated that cycloheptatriene-fused pyrrolidone $4 \mathrm{a}$ can be hydrogenated in the presence of catalytic amounts of $\mathrm{Pd} / \mathrm{C}$, providing compound 7 in good yield while retaining the stereochemical information of $\mathbf{4 a}$ (Scheme 5).<smiles>[13CH3]N1C(=O)[C@H](c2ccccc2)[C@@H]2C=CC=CC=C21</smiles>

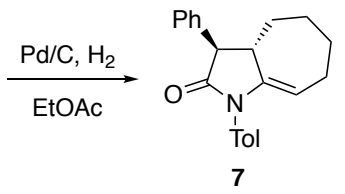

$94 \%$ yield $>20: 1 \mathrm{dr}$

Scheme 5. Catalytic hydrogenation of $4 a$.

The catalytic cycle proposed for this transformation, based on previous reports of isothiourea-mediated cyclizations, ${ }^{[21]}$ is depicted in Scheme 6. The events start upon in situ formation of the mixed anhydride $\mathbf{A}$ from $\mathbf{3}$ and pivaloyl chloride. This intermediate reacts with the isothiourea $\mathbf{1 b}$ to form the corresponding acyl ammonium species $\mathbf{B}$, which is deprotonated by the pivalate to generate the corresponding enolate (C; DBU acts as a shuttle base to deprotonate the pivalic acid generated $^{[22]}$ ). Subsequently, 1,8-conjugate addition of the azaheptafulvene $\mathbf{2}$ onto $\mathbf{C}$ gives rise to $\mathbf{D}$, which readily cyclizes to generate the desired cycloadduct 4 with concomitant release of the catalyst that can then engage in the next cycle. It is worth noting that at present we cannot rule out a concerted mechanism, but literature precedents suggest ${ }^{[16 \mathrm{~d}]}$ that a stepwise mechanism is operative with highly polarized substrates.

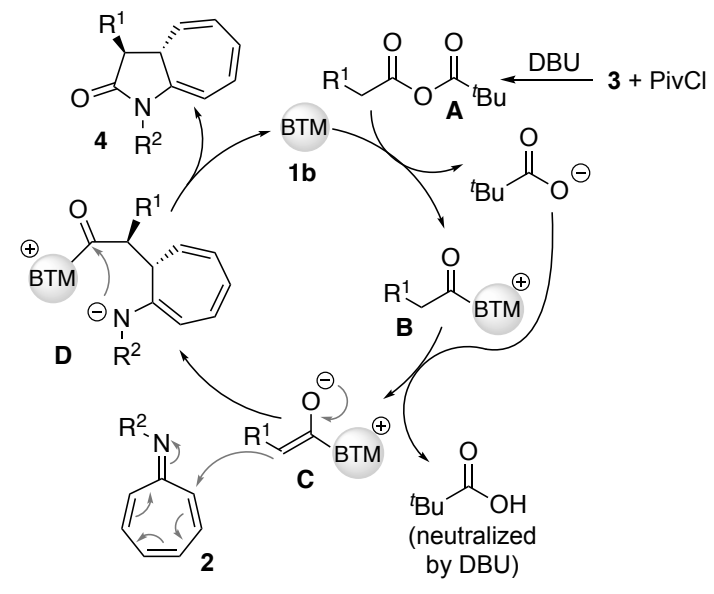

Scheme 6. Proposed catalytic pathway.

In conclusion, we have developed the first asymmetric organocatalytic [8+2] annulation reaction between azaheptafulvenes and in situ activated arylacetic acids for the direct synthesis of enantioenriched cycloheptatriene-fused pyrrolidone derivatives. The transformation is promoted by a supported isothiourea catalyst that can be recycled at least 7 times by simple filtration. Moreover, we have studied the derivatization of the resulting [8+2] cycloadducts by means of a [4+2] cycloaddition to give bridged-polycyclic products in a regioselective manner. The $[8+2] /[4+2]$ cycloaddition sequence reported herein represents an efficient stereoselective synthetic 
approach to polycyclic compounds. Further synthetic application of this methodology is currently underway.

\section{Acknowledgements}

Financial support from CERCA Programme/Generalitat de Catalunya, MINECO (CTQ2015-69136-R, AEI/MINECO/FEDER, UE and Severo Ochoa Excellence Accreditation 2014-2018, SEV-2013-0319) and DEC Generalitat de Catalunya (Grant 2014SGR827) is acknowledged. The CELLEX Foundation is acknowledged for financing the High Throughput Experimentation (HTE) laboratory.

Keywords: higher order cycloadditions $\cdot[8+2]$ cycloaddition $•$ isothioureas $\cdot$ enantioselective catalysis $\bullet$ immobilized catalysts

[1] For recent reviews on cyclization reactions, see: a) S. Ma (Ed.), Handbook of cyclization reactions, Wiley-VCH, Weinheim, Germany, 2009; b) A Moyano, R. Rios, Chem. Rev. 2011, 111, 4703-4832; c) C. N. Ungarean, E. H. Southgate, D. Sarlah, Org. Biomol. Chem. 2016, 14, 5454-5467; d) M.-C. Tang, Y. Zou, K. Watanabe, C. T. Walsh, Y. Tang, Chem. Rev. 2017, $117,5226-5333$

[2] a) R. Hoffmann, R. B. Woodward, J. Am. Chem. Soc. 1965, 87, 2046-2048; b) R. Hoffmann, R. B. Woodward, J. Am. Chem. Soc. 1965, 87, 4388-4389; c) R. Huisgen, Angew. Chem. Int. Ed. 1968, 7, 321-328.

[3] For recent examples, see: a) J. Burés, A. Armstrong, D. G. Blackmond, J. Am. Chem. Soc. 2011, 133, 8822-8825; b) Ł. Albrecht, G. Dickmeiss, F. C Acosta, C. Rodríguez-Escrich, R. L. Davis, K. A. Jørgensen, J. Am. Chem. Soc. 2012, 134, 2543-2546; c) G. Talavera, E. Reyes, J. L. Vicario, L. Carrillo, Angew. Chem. Int. Ed. 2012, 51, 4104-4107; d) S. R. Smith, J. Douglas, H. Prevet, P. Shapland, A. M. Z. Slawin, A. D. Smith, J. Org. Chem. 2014, 79, 1626-1639.

[4] a) R. Huisgen, Angew. Chem. Int. Ed. 1963, 2, 633-645; for recent examples, see: b) S. Vellalath, K. N. Van, D. Romo, Angew. Chem. Int. Ed. 2013, 52, 13688-13693; c) C. Guo, M. Fleige, D. Janssen-Müller, C. G. Daniliuc, F. Glorius, Nature Chem. 2015, 7, 842-847; d) L. Hesping, A. Biswas, C. G. Daniliuc, C. Mück-Lichtenfeld, A. Studer, Chem. Sci. 2015, 6, 1252-1257; e) B.-S. Li, Y. Wang, Z. Jin, Y. R. Chi, Chem. Sci. 2015, 6, 6008-6012.

[5] a) O. Diels, K. Alder, Justus Liebigs Annalen der Chemie 1928, 460, 98122; b) D. L. Boger, Chem. Rev. 1986, 86, 781-793; c) K. C. Nicolaou, S. A. Snyder, T. Montagnon, G. Vassilikogiannakis, Angew. Chem. Int. Ed. 2002, 41, 1668-1698.

[6] a) J. H. Rigby, Acc. Chem. Res. 1993, 26, 579-585; b) M. Harmata, Acc. Chem. Res. 2001, 34, 595-605; c) K. E. O. Ylijoki, J. M. Stryker, Chem. Rev. 2013, 113, 2244-2266.

[7] For a recent insightful essay, see: T. A. Palazzo, R. Mose, K. A. Jørgensen, Angew. Chem. Int. Ed. 2017, 56, 10033-10038.

[8] a) K. N. Houk, L. J. Luskus, N. S. Bhacca, J. Am. Chem. Soc. 1970, 92, 6392-6394; b) M. N. Paddon-Row, R. N. Warrener, Tetrahedron Lett. 1974, 15, 3797-3800; c) I.-m. Tegmo-Larsson, K. N. Houk, Tetrahedron Lett. 1978, 19, 941-944; d) C. Y. Liu, S. T. Ding, J. Org. Chem. 1992, 57, 45394544; e) C. Y. Liu, S. T. Ding, S. Y. Chen, C. Y. You, H. Y. Shie, J. Org Chem. 1993, 58, 1628-1630; f) J. H. Rigby, H. S. Ateeq, N. R. Charles, S. V. Cuisiat, M. D. Ferguson, J. A. Henshilwood, A. C. Krueger, C. O. Ogbu, K. M. Short, M. J. Heeg, J. Am. Chem. Soc. 1993, 115, 1382-1396; g) P. Li, H. Yamamoto, J. Am. Chem. Soc. 2009, 131, 16628-16629.

[9] For examples of successful cases: a) B. M. Trost, P. J. McDougall, O. Hartmann, P. T. Wathen, J. Am. Chem. Soc. 2008, 130, 14960-14961; b) Q.-H. Li, L. Wei, C.-J. Wang, J. Am. Chem. Soc. 2014, 136, 8685-8692; c) H.-L. Teng, L. Yao, C.-J. Wang, J. Am. Chem. Soc. 2014, 136, 4075-4080.

[10] a) H. Prinzbach, H.-J. Herr, W. Regel, Angew. Chem. Int. Ed. 1972, 11, 131-133; b) K. Komatsu, M. Fujimori, K. Okamoto, Tetrahedron 1977, 33, 2791-2797; c) C. Y. Liu, J. Mareda, K. N. Houk, F. R. Fronczek, J. Am. Chem. Soc. 1983, 105, 6714-6715; d) C.-Y. Liu, D. A. Smith, K. N. Houk, Tetrahedron Lett. 1986, 27, 4881-4884; e) V. Nair, K. G. Abhilash, A. T. Biju, E. Suresh, Synthesis 2007, 1833-1836.
[11] a) J. Ciabattoni, H. W. Anderson, Tetrahedron Lett. 1967, 8, 3377-3381; b) W. E. Truce, C.-I. M. Lin, J. Am. Chem. Soc. 1973, 95, 4426-4428; c) E. Garfunkel, I. D. Reingold, J. Org. Chem. 1979, 44, 3725-3725; d) M. Julino, U. Bergstraesser, M. Regitz, J. Org. Chem. 1995, 60, 5884-5890; e) N. Liu, W. Song, C. M. Schienebeck, M. Zhang, W. Tang, Tetrahedron 2014, 70, 9281-9305.

[12] a) T. Machiguchi, M. Hoshino, S. Ebine, Y. Kitahara, J. Chem. Soc., Chem. Commun. 1973, 196-196; b) T. Machiguchi, H. Otani, Y. Ishii, T. Hasegawa, Tetrahedron Lett. 1987, 28, 203-206; c) T. Machiguchi, T. Hasegawa, S. Itoh, H. Mizuno, J. Am. Chem. Soc. 1989, 111, 1920-1921; d) T. Machiguchi, T. Hasegawa, Y. Ishii, S. Yamabe, T. Minato, J. Am. Chem. Soc. 1993, 115, 11536-11541; e) T. Machiguchi, T. Hasegawa, H. Otani, S. Yamabe, H. Mizuno, J. Am. Chem. Soc. 1994, 116, 407-408.

[13] a) S. Ken-ichi, K. Shoji, K. Shuji, Chem. Lett. 1977, 6, 861-864; b) W. E. Truce, J. P. Shepherd, J. Am. Chem. Soc. 1977, 99, 6453-6454; c) V. Nair, K. G. Abhilash, Tetrahedron Lett. 2006, 47, 8707-8709; d) W. Chen, Y.-L. Bai, Y.-C. Luo, P.-F. Xu, Org. Lett. 2017, 19, 364-367.

[14] a) L. E. Overman, E. J. Jacobsen, R. J. Doedens, J. Org. Chem. 1983, 48, 3393-3400; b) J. Daub, G. Hirmer, L. Jakob, G. Maas, W. Pickl, E. Pirzer, K. M. Rapp, Chem. Ber. 1985, 118, 1836-1856; c) X. Zhao, E. Zhang, Y.Q. Tu, Y.-Q. Zhang, D.-Y. Yuan, K. Cao, C.-A. Fan, F.-M. Zhang, Org. Lett. 2009, 11, 4002-4004; d) X. Zhou, T. Xiao, Y. Iwama, Y. Qin, Angew. Chem. Int. Ed. 2012, 51, 4909-4912.

[15] W. von E. Doering, D. W. Wiley, Tetrahedron 1960, 11, 183-198.

[16] a) K. Ito, K. Saito, K. Takahashi, Bull. Chem. Soc. Jpn. 1992, 65, 812-816; b) K. Kumar, A. Kapur, M. P. S. Ishar, Org. Lett. 2000, 2, 787-789; c) J. Barluenga, J. García-Rodríguez, S. Martínez, Á. L. Suárez-Sobrino, M. Tomás, Chem. Asian J. 2008, 3, 767-775; d) M. L. Lage, I. Fernández, M. A. Sierra, M. R. Torres, Org. Lett. 2011, 13, 2892-2895; e) F. Esteban, R. Alfaro, F. Yuste, A. Parra, J. L. G. Ruano, J. Alemán, Eur. J. Org. Chem. 2014, 1395-1400.

[17] M. Xie, X. Liu, X. Wu, Y. Cai, L. Lin, X. Feng, Angew. Chem. Int. Ed. 2013, 52, 5604-5607.

[18] R. Mose, G. Preegel, J. Larsen, S. Jakobsen, E. H. Iversen, K. A. Jørgensen, Nature Chem. 2017, 9, 487-492.

[19] a) M. J. Gaunt, C. C. C. Johansson, Chem. Rev. 2007, 107, 5596-5605; b) D. Belmessieri, L. C. Morrill, C. Simal, A. M. Z. Slawin, A. D. Smith, J. Am. Chem. Soc. 2011, 133, 2714-2720; for recent selected examples, see: c) C. Simal, T. Lebl, A. M. Z. Slawin, A. D. Smith, Angew. Chem. Int. Ed. 2012 51, 3653-3657; d) M. E. Abbasov, B. M. Hudson, D. J. Tantillo, D. Romo, J. Am. Chem. Soc. 2014, 136, 4492-4495; e) J. Izquierdo, M. A. Pericàs, ACS Catal. 2016, 6, 348-356; f) K. N. Van, L. C. Morrill, A. D. Smith, D. Romo, in Lewis Base Catalysis in Organic Synthesis, Wiley- $\mathrm{VCH}$, Weinheim, Germany, 2016, pp. 527-654; g) S. Wang, J. Izquierdo, C. Rodríguez-Escrich, M. A. Pericàs, ACS Catal. 2017, 7, 2780-2785.

[20] Structures deposited as CCDC 1562521 (4b) and CCDC 1562520 (6b).

[21] a) L. C. Morrill, T. Lebl, A. M. Z. Slawin, A. D. Smith, Chem. Sci. 2012, 3, 2088-2093; b) C. M. Young, D. G. Stark, T. H. West, J. E. Taylor, A. D. Smith, Angew. Chem. Int. Ed. 2016, 55, 14394-14399; c) J. Song, Z.-J. Zhang, L.-Z. Gong, Angew. Chem. Int. Ed. 2017, 56, 5212-5216.

[22] a) S. Xu, I. Held, B. Kempf, H. Mayr, W. Steglich, H. Zipse, Chem. Eur. J. 2005, 11, 4751-4757; b) K. Nakata, K. Gotoh, K. Ono, K. Futami, I. Shiina, Org. Lett. 2013, 15, 1170-1173. 


\section{Entry for the Table of Contents}

\section{COMMUNICATION}

An isothiourea-catalyzed peri- and enantioselective [8+2] cycloaddition between chiral ammonium enolates and azaheptafulvenes is presented. Enantioenriched cycloheptatrienes fused to a pyrrolidone ring can be produced with this novel methodology. Derivatization of these cycloadducts via regio- and diastereoselective Diels-Alder reaction allows the production of architecturally complex polycyclic compounds in a straightforward manner.
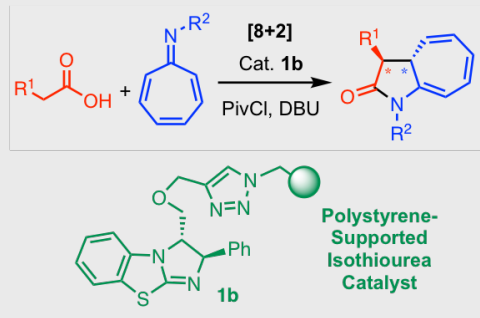

- Periselective [8+2] Cycloaddition - Regio- and Enantioselective - 19 examples

- Up to $85 \%$ yield, $98 \%$ ee

- Derivatization of the Cycloadducts - Recyclable Catalyst
Shoulei Wang, Carles Rodríguez-

Escrich and Miquel A. Pericàs*

Page No. - Page No.

Catalytic Asymmetric [8+2]

Annulation Reactions Promoted by a

Recyclable Immobilized Isothiourea 